\title{
Numerical Simulations of Premixed Cool Flames of Dimethyl Ether/Oxygen Mixtures
}

\author{
Yiguang Ju, Christopher B. Reuter, and Sang Hee Won
}

Department of Mechanical and Aerospace Engineering, Princeton University, Princeton, NJ 08544, USA

\author{
Corresponding Author \\ Yiguang Ju \\ Mechanical and Aerospace Engineering \\ Princeton University \\ Princeton, NJ 08544, USA \\ Phone: +1-609-258-5644 \\ Fax: +1-609-258-6233 \\ Email: yju@princeton.edu
}

Keywords: Cool flames, flame speed, extinction limit, dimethyl ether, ozone

1

(C) 2015. This manuscript version is made available under the Elsevier user license http://www.elsevier.com/open-access/userlicense/1.0/ 


\begin{abstract}
The formation and dynamics of premixed cool flames are numerically investigated by using a detailed kinetic mechanism of dimethyl ether mixtures in both freely-propagating and stretched counterflow flames with and without ozone sensitization. The present study focuses on the dynamics and transitions between cool flames and high temperature flames. The impacts of mixture temperature, inert gas temperature, and ozone concentration on low temperature ignition, cool flame formation, and flammable regions of different flame regimes are investigated. For the freely-propagating flames, three different flame structures (high temperature flames, double flames, and cool flames) are found. The present study shows that the flammability limit of dimethyl ether is significantly extended by the appearance of cool flames and that the conventional concept of the flammability limit of a high temperature flame ought to be reconsidered. Furthermore, the results demonstrate that the cool flame propagation speed can be significantly higher than that of near-limit high temperature flames and that ozone addition dramatically accelerates the formation of cool flames at low temperatures and extends the flammability limit. A schematic of a modified flammability limit diagram including both high temperature flames and cool flames is proposed. For stretched counterflow flames, the results also show that multiple flame regimes exist with and without ozone addition. It is demonstrated that at the same mixture enthalpy, ozone addition kinetically extends the cool flame extinction limit to a higher stretch rate. Moreover, with ozone addition, two different cool flame transition regimes: a low temperature ignition transition and a direct cool flame transition without an ignition limit at higher temperature, are predicted. The present results suggest that cool flames can be an important combustion process in affecting flammability limits and flame regimes as the mixture temperature, turbulent mixing, and radical production/recirculation are increased. The results also provide guidance in observing self-sustaining premixed cool flames in experiments.
\end{abstract}

\title{
1. Introduction
}

Cool flames have long been considered a key process responsible for engine knock and are also an important phenomenon for fire safety $[1,2,3,4,5,6]$. Since the first discovery of cool flames two centuries ago [7,8], extensive efforts have been made to observe cool flames by using various flame geometries including heated surfaces and heated burners [8,9,10,11], stirred reactors $[12,13,14]$, heated flow reactors $[1,8,15,16,17]$, rapid compression machines [18], counterflow flames [19], droplets [6,20,21], and plasma-assisted flames [22,23]. Despite that many of the 
observed cool flames were oscillatory, transient, and strongly affected by flame-surface interaction, insights into cool flame spectroscopy, negative temperature coefficient (NTC) chemistry, heat release, and the cool flame peninsula in the temperature/pressure domain were obtained [12,14]. Nevertheless, few studies have been carried out on cool flame dynamics, extinction, and flammability limits. Much of our knowledge today about flame propagation speeds, flame structures, extinction limits, and flammability limits is still limited to high temperature flames [24]. Due to the difficulty in establishing self-sustaining cool flames, a detailed and fundamental understanding of cool flame dynamic behaviors has not been well established.

Recently, a self-sustaining n-heptane cool diffusion flame was experimentally observed for the first time by using ozone sensitization in a counterflow flame over a broad range of flow residence times [19]. The flame structures and extinction limits were quantitatively measured in this study. The results showed that ozone addition extended the flammable region of cool flames and allowed self-sustaining cool flames to be observed on a laboratory flame scale. In other studies, Law and Zhao numerically modeled the NTC effect on n-heptane/air ignition in a diffusion counterflow flame [25]. Their results demonstrated the existence of NTC-affected ignition. In nheptane droplet combustion experiments, Nayagam et al. [6] reported the dual modes of combustion and extinction and presented a hypothesis of cool flame formation in a microgravity environment. In a related n-heptane droplet study, Farouk et al. [21] numerically modeled oscillatory cool flames governed by radiation heat loss and conductive heat loss from flame to droplet. However, the above studies were all limited to diffusion flames.

For premixed cool flames, Maruta and coworkers recently $[16,17]$ studied the stabilization limits of cool flames by using a burner-heated microchannel. Unfortunately, in this geometry the wall temperature gradient and flame-wall coupling strongly dictate the flame stability, making it difficult to address how fast a cool flame can propagate and what the relation is between the flammability limits of high temperature flames and cool flames.

With the expected increases in pressure and initial mixture temperature in future engines, there is a chance that cool flames could not only affect engine knocking [4,5] but also influence heat release rates via turbulence-chemistry interaction. In a previous numerical simulation of sparkassisted homogeneous charge compression ignition (HCCI) [26], unsteady cool flame propagation was observed. In a recent study of low temperature turbulent combustion by using a reactorassisted turbulent slot (RATS) burner [27], it was demonstrated that low temperature ignition and cool flame chemistry significantly changed turbulent flame speeds and structures.

Unfortunately, the previous studies on flame speeds, extinction limits, and flammability limits for stretched and unstretched flames were often limited to high temperature flames. It was 
not revealed how fast a cool flame could propagate compared to the high temperature flames, whether it burned leaner than a high temperature flame, or how mixture temperature and radical addition affected its extinction and flammability limits [37].

Motivated by the above discussions, the goal of this study is to simulate numerically the formation of premixed cool flames for both freely-propagating and stretched counterflow flames by using a detailed kinetic mechanism of dimethyl ether/oxygen mixtures with and without ozone sensitization. First, we investigate the propagation speeds, structures, and flammability limits of dimethyl ether/oxygen cool flames and high temperature flames. The effects of mixture temperature and ozone addition on the flammability limits of and transitions between high temperature flames and cool flames are examined, and a schematic of a new flammability diagram including both high temperature flames and cool flames is presented. Flame structures, reaction pathways, and the sensitivity of different flame regimes to transport properties are discussed. Second, we simulate the formation of stretched counterflow cool flames. Different flame regimes are investigated, and the effects of inert gas temperature on the flammable region of cool flames and the transition to cool flames through ignition are examined. Finally, we discuss possibilities for experimental observations of premixed cool flames in the counterflow geometry.

\section{Numerical Models}

In this study, we consider both the one-dimensional freely-propagating premixed flame and the stretched counterflow premixed flame geometries (Figures 1a and 1b). The freely-propagating flame is employed to predict the propagation speeds and the flammability limits of cool flames and high temperature flames (HTF). The counterflow flame is computed to understand the flammable region of cool flames in relation to flame stretch and to provide guidance for future experimental studies. Note that for some cool flame computations, the downstream computation domain is changed to $1.5 \mathrm{~cm}$ to save computational time.

Dimethyl ether (DME) is one of the simplest hydrocarbon fuels which possesses low temperature chemistry and whose kinetic mechanism has been widely investigated [28,29,30,31]. Thus, we have chosen DME as a representative of large hydrocarbon fuels with low temperature chemistry. In our previous diffusion cool flame study [19], it was found that ozone can promote the formation of diffusion cool flames. Therefore, for the purpose of providing experimental guidance and understanding how radical addition in turbulent mixing and plasma discharge affects cool flames, we use a mixture of $(1-x) \mathrm{O}_{2}+x \mathrm{O}_{3}(x=0-0.08)$ as the oxidizer. This formulation preserves the molar oxidizer/fuel ratio as ozone is added. The mixture temperature and ozone concentration are varied to examine the impact of initial reactant temperature and radical addition 
on cool flame formation. In the premixed counterflow flames, a heated nitrogen stream is used to stabilize the cool flame.

For kinetic modeling of ozone decomposition, the elementary mechanism proposed by Ombrello et al. [32] with an update of the ozone decomposition rate [23] is used. For DME oxidation, the kinetic mechanism of Zhao et al. [31] with the recent update of $\mathrm{C}_{0}$ and $\mathrm{C}_{1}$ subchemistry as well as the DME decomposition reaction rate [29] is employed. Although this model has some over-prediction of low temperature fuel oxidation, it still able to qualitatively predict the dynamics of cool flames. In the radiation calculation, we used the optically thin radiation model for computational efficiency and simplicity. The Planck mean absorption coefficients are calculated for $\mathrm{CH}_{4}, \mathrm{CO}_{2}, \mathrm{H}_{2} \mathrm{O}$, and $\mathrm{CO}$ using the statistical narrow-band model found in [33]. The radiation from $\mathrm{CH}_{2} \mathrm{O}$ and other intermediate species is neglected. For all calculations, the pressure is fixed at $1 \mathrm{~atm}$. All steady-state solutions of unstretched freely-propagating flames and stretched counterflow flames are computed by using a revised version of the Chemkin III code [34] with an improved arc-length continuation method [33]. For the convergence criteria, the relative and absolute errors of all species mole fractions and temperature are, respectively, $10^{-4}$ and $10^{-9}$.

\section{Numerical Results}

\subsection{Flame Structure and Flame Regimes of Freely-Propagating Premixed Cool Flames}

We first examine the effects of reactant temperature on the flame regimes of freelypropagating premixed $\mathrm{DME} / \mathrm{O}_{2}$ flames. Fig. 2a shows the dependence of the maximum flame temperature on the equivalence ratio. At an unburned mixture temperature of $\mathrm{T}_{0}=300 \mathrm{~K}$, the flame temperature decreases with decreases in the equivalence ratio $(\Phi)$. At a critical equivalence ratio $(\Phi=0.0785)$, the maximum flame temperature becomes so low $\left(\mathrm{T}_{\mathrm{f}}=1160 \mathrm{~K}\right)$ that the important high temperature chain-branching reactions (such as $\mathrm{H}+\mathrm{O}_{2}=\mathrm{OH}+\mathrm{O}$ ) slow down significantly. At this point, flame extinction occurs and no solution exists below this critical equivalence ratio. This is the so-called the lean flammability limit of the $\mathrm{DME} / \mathrm{O}_{2}$ flame. In Fig. 2a, flammability limits appear as the turning points in the S-curves at which a decrease in equivalence ratio results in exponential decrease in flame temperature and flame speed.

However, when the reactant temperature is raised to $530 \mathrm{~K}$, at which significant low temperature reactivity exists for DME at atmospheric pressure [30], the flame temperature dependence on equivalence ratio changes dramatically. When the flame temperature is high (see the normal flame branch, $a b$, in Fig. 2a), the flame temperature decreases as the equivalence ratio decreases. At $1418 \mathrm{~K}(\Phi=0.0768)$, the high temperature flame extinguishes. Therefore, compared to the flammability limit for the $300 \mathrm{~K}$ case, the increase in reactant temperature to $530 \mathrm{~K}$ only 
slightly extends the lean flammability limit of the high temperature flame. However, unlike the $300 \mathrm{~K}$ case, at $530 \mathrm{~K}$ a new "double flame" branch $(b c)$ appears in which the flame has two separated low and high temperature flame fronts. In this double flame structure, the hot flame front follows the cool flame front in space. Between these two flame fronts, the radiation heat loss and the heat release from chemical reaction compete with each other. As the equivalence ratio increases, the maximum flame temperature of the double flame decreases and the distance between the separated hot flame and cool flame increases, eventually leading to the quenching of the hot flame. At a critical equivalence ratio (point $c, \Phi=0.288$, flame temperature $\mathrm{T}_{\mathrm{f}}=1004 \mathrm{~K}$ ), the double flame structure disappears (i.e., the high temperature flame moves out of the computation domain) and another new flame branch ( $c d$, the cool flame branch) emerges. Unlike in the double flame regime, the flame temperature of the cool flame decreases monotonically with decreases in equivalence ratio and can exist at an equivalence ratio far below the flammability limit of the high temperature flame (HTF). Note that the size of the computational domain only slightly affects the transition from the double flame to cool flame. For example, an increase in the exit flow computational boundary (right edge of Fig. 1a) from $1.5 \mathrm{~cm}$ to $4 \mathrm{~cm}$ changes the double/cool transition from $\Phi=0.288$ to 0.296 . Qualitatively, it does not change the predicted flame dynamics and regimes. Thus, in summary, at higher reactant temperatures the $\mathrm{DME} / \mathrm{O}_{2}$ flame has three different flame regimes - the high temperature normal flame, the intermediate temperature double flame, and the low temperature cool flame. The cool flame significantly extends the flammability limit of the normal flame. This may be a very important finding for fire safety because the quenching limit of a propagating flame can no longer be determined by only considering the high temperature flame quenching limit.

Fig. $2 b$ shows the corresponding unstretched laminar flame speeds $\left(S_{L}\right)$ of these three different flame regimes. In the case of a reactant temperature of $300 \mathrm{~K}$, the flame speed decreases as the equivalence ratio decreases. At the flammability limit, the flame speed is about $1.5 \mathrm{~cm} / \mathrm{s}$, which is consistent with the predicted speeds at the flammability limit of other hydrocarbons [24]. This flame speed is so low that radiation will quench any possible double flames. However, in the $\mathrm{T}_{0}=530 \mathrm{~K}$ case, the flame speed at the flammability limit of the high temperature normal flame is very high $(15.4 \mathrm{~cm} / \mathrm{s})$. As the $\mathrm{T}_{0}=530 \mathrm{~K}$ flame passes the high temperature flame flammability limit, it transitions into a double flame and its flame speed actually slightly increases with the increase of equivalence ratio. Furthermore, it can be seen that in the cool flame region, the cool flame speed is fairly high and only weakly dependent on the flame temperature. At equivalence ratios greater than the hot flame flammability limit, the cool flame speed can reach up to $22 \mathrm{~cm} / \mathrm{s}$, which is faster than most of the near-limit high temperature flames. This is primarily due to the 
higher fuel concentrations and lower activation energies of these far-limit cool flames. Therefore, the existence of cool flames not only extends the flammability limit of the normal high temperature flame but also modifies the flame speed at ultra-lean conditions.

Fig.2 (c) shows the dependence of flame speed on equivalence ratio for $\mathrm{DME} / \mathrm{O}_{2}$ freely propagating premixed flames at unburned mixture temperatures of $300 \mathrm{~K}, 400 \mathrm{~K}$, and $530 \mathrm{~K}$, respectively on fuel rich side. It is interesting to note that the high temperature flame (HTF) only exists up to equivalence ratio near 3 . However, the cool flame can exist in a broad range of fuel rich conditions. Furthermore, it is seen that the transition from high temperature flame to cool flame is a direct transition without a flame extinction turning point. In addition, with the increase of mixture temperature, the cool flame speed increases and the flammable region extends to richer conditions.

Figs. 2a, 2b and 2c suggest that for a fuel with low temperature chemistry, the conventional concept of the lean flammability limit and the flame regime diagram may not apply. Since the low temperature reactivity increases with the equivalence ratio, on the fuel-rich side the existence of cool flames will also extend the flammability limit of high temperature flames. In order to highlight the important features of these flame regimes for fuels with cool flame chemistry, a flame regime and flammability limit diagram is shown in Fig. 3. For fuels without the possibility of cool flames (dashed line), the normal hot flame fully defines the lean and rich flammability limits. However, for a fuel with low temperature chemistry, cool flames give a new set of flammability limits which are much more extreme than the flammability limits of the normal flame (HTF). Note that although the quantitative prediction of the flammability limits and the transitions between different flame regimes may be affected by the computational domain, chemical mechanism, and radiation models, these factors should not affect the general conclusions made above.

In order to understand the differences between the three different flame regimes - the high temperature normal flame, the intermediate temperature double flame, and the low temperature cool flame - the flame structures of these regimes at the same equivalence ratio of $\Phi=0.1$ are shown in Figs. 4a, 4b, and 4c. For the high temperature flame (Fig. 4a), the flame has a very thin structure $(2 \mathrm{~mm})$ within which there is a rapid temperature rise of more than $1000 \mathrm{~K}$ and a high concentration of $\mathrm{OH}$ radicals. At the end of the reaction zone, all of the fuel is oxidized to $\mathrm{H}_{2} \mathrm{O}$ and $\mathrm{CO}_{2}$. This is typical for the structure of a high temperature flame.

Fig. $4 \mathrm{~b}$ shows the structure of the intermediate temperature double flame (the $b c$ branch of Fig. 2a), consisting of a leading cool flame in the front $(X=0 \mathrm{~cm})$ and a separated high temperature reaction zone in the rear at $\mathrm{X}=1.4 \mathrm{~cm}$. The leading cool flame only has a small temperature rise ( $200 \mathrm{~K}$ ), after which most of the fuel is oxidized to $\mathrm{CO}, \mathrm{CH}_{2} \mathrm{O}$ and $\mathrm{HCOOH}$ with only a small 
amount of $\mathrm{CO}_{2}$ formation. The key radical in the cool flame is $\mathrm{HO}_{2}$. After the cool flame front, $\mathrm{H}_{2} \mathrm{O}_{2}$ is formed from $\mathrm{HO}_{2}$ and the temperature gradually increases. At a critical temperature ( 810 $\mathrm{K}$ ), the chain-branching reaction $\mathrm{H}_{2} \mathrm{O}_{2}=2 \mathrm{OH}$ is accelerated, leading to a rapid rise in $\mathrm{OH}$ radical concentration and temperature consequently to form a hot flame governed by high temperature chemistry. Note that the heat release of the hot flame is too far away from the leading cool flame to affect the flame propagation speed. As shown in Fig. $2 b$, the propagation speed of the intermediate temperature double flame is effectively the same as that of the cool flame. The distance between the hot and cool flame fronts is governed by competition between radiative cooling and chemical heat release coupled with transport. For double flames at a higher maximum temperature than the one in Fig. 4b, chemical heat release is more dominant and the cool and hot flame fronts are closer together. On the other hand, as radiative cooling becomes more and more dominant, the hot flame moves away from the cool flame and eventually exits the computational domain, resulting in a purely cool flame structure (Fig. 4c). Note that the double flame structure was also observed in our previous unsteady flame simulation of spark-initiated HCCI combustion [26], where a hot flame changed into a double flame structure due to higher flame speed of the cool flame at that specific condition. Therefore, the observed steady state double flame structure also exists in unsteady flames at engine conditions.

Fig. 4c shows the flame structure of the cool flame ( $c d$ branch in Fig. 2). Unlike the intermediate temperature double flame, the cool flame only has a single temperature rise caused by the cool flame front. The intermediate temperature double flame may not be a stable flame structure, that is, a small perturbation can cause the flame to transition either to the high temperature flame or to the cool flame. Therefore, in this study, we limit our focus only to the high temperature flames and the cool flames. The stability of these flames will be addressed in future studies.

In order to demonstrate that the computed double flame and cool flame in Figs. $4 \mathrm{~b}$ and $4 \mathrm{c}$ have a well-defined diffusion-reaction flame structure and are not simply auto-ignition fronts, Figs. $5 \mathrm{a}, 5 \mathrm{~b}$, and $5 \mathrm{c}$ show the corresponding distributions of the normalized, volumetric conduction heat transfer rate and the chemical heat release rate for the high temperature flame, double flame and cool flame, respectively. In these figures, both the volumetric conduction heat transfer rate and the chemical heat release rate are normalized by the either the peak chemical heat release rate of the high temperature flame or the cool flame in the computation domain:

$$
\text { Normalized heat conduction rate }=\frac{\frac{d}{d X}\left(\lambda \frac{d T}{d X}\right)}{\operatorname{Max}\left(\sum_{i} h_{i} \omega_{i}\right)}
$$


Normalized chemical heat release rate $=\frac{\sum_{i} h_{i} \omega_{i}}{\operatorname{Max}\left(\sum_{i} h_{i} \omega_{i}\right)}$

Where $T$ and $X$ are, respectively, the temperature and streamwise coordinate; $\lambda, \mathrm{h}_{\mathrm{i}}$, and $\omega_{\mathrm{i}}$ are the heat conductivity, enthalpy, and reaction rate of the $i$ th species.

As seen in the Fig. 5a for the high temperature flame, there are two peaks of the heat release rate. The leading smaller peak is the low temperature reaction zone, and the following larger one is the high temperature reaction zone. Note that in the reaction-diffusion zone, the magnitudes of heat conduction rate and chemical heat release rate are of the same order (close to unity). In the preheating zone, however, the heat conduction rate is not only larger than the ignition heat release rate but also is located in front of the auto-ignition zone. This is the typical self-sustained diffusionreaction (or heat conduction-ignition) flame structure. It should be noted that even for high temperature flames, at near-limit conditions low temperature chemistry affects the heat release rate of the flame and modifies the conductive heat transfer rate.

For the double flame, Fig. 5b shows that both the leading cool flame and the following high temperature flame have similar diffusion-reaction flame structures. These flame structures are essentially no different from that of the high temperature flame in Fig. 5a. Therefore, they are both caused by heat conduction-induced ignition and not by auto-ignition. For the cool flame, Fig. 5c also clearly shows that it is the heat conduction from the cool flame reaction zone to the unburned mixture that raises the temperature and causes ignition in the cool flame. Moreover, the chemical heat release rate before the preheating, convection-diffusion zone is negligible. Therefore, the computed cool flame is in fact a self-sustaining cool flame front and not an ignition wave.

The sensitivity of the cool flame speed to select elementary reactions is shown in Fig. 6a. It is seen that the flame speed is sensitive to the typical low temperature reactions involving radical formation of $\mathrm{OH}, \mathrm{HO}_{2}$, and $\mathrm{R}\left(\mathrm{CH}_{3} \mathrm{OCH}_{2}\right) ; \mathrm{RO}_{2}\left(\mathrm{CH}_{3} \mathrm{OCH}_{2} \mathrm{O}_{2}\right)$ isomerization to QOOH $\left(\mathrm{CH}_{2} \mathrm{OCH}_{2} \mathrm{O}_{2} \mathrm{H}\right)$; second $\mathrm{O}_{2}$ addition to QOOH leading to the formation of $\mathrm{O}_{2} \mathrm{CH}_{2} \mathrm{OCH}_{2} \mathrm{O}_{2} \mathrm{H}$; and the decomposition of ketohydroperoxide $\left(\mathrm{HO}_{2} \mathrm{CH}_{2} \mathrm{OCHO}\right)$.

The sensitivities of flame speed on the species mass diffusivity of the high temperature flame (HTF) and the cool flame are compared in Fig. 6b. For the high temperature flame, the flame speed is mainly sensitive to the diffusivities of the reactants $\left(\mathrm{O}_{2}\right.$ and $\left.\mathrm{DME}\right)$ and products $\left(\mathrm{H}_{2} \mathrm{O}, \mathrm{CO}_{2}\right)$. However, for the cool flame, the flame speed becomes more sensitive to the diffusivities of intermediate species such as $\mathrm{CH}_{2} \mathrm{O}, \mathrm{HO}_{2} \mathrm{CH}_{2} \mathrm{OCHO}, \mathrm{CO}$, and $\mathrm{H}_{2} \mathrm{O}_{2}$. It should be noted that the diffusion sensitivities of the cool flame to fuel, $\mathrm{CH}_{2} \mathrm{O}$, and $\mathrm{HO}_{2} \mathrm{CH}_{2} \mathrm{OCHO}$ indicate that the Lewis 
number of the DME cool flame remains greater than unity. This will be shown later by the dependence of flame temperature and the location of extinction in the counterflow flames.

Therefore, for $\mathrm{DME} / \mathrm{O}_{2}$ mixtures, an increase in the reactant temperature can lead to the formation of cool flames. These cool flames can significantly extend the lean flammability limit, increase the near-limit flame speed, and change the flame speed sensitivity to reactions and transport properties.

\subsection{Effects of Ozone on Freely-Propagating Premixed Cool Flames}

As shown above, in order to observe a $\mathrm{DME} / \mathrm{O}_{2}$ cool premixed flame, the unburned mixture temperature has to be increased to $530 \mathrm{~K}$, which falls into the temperature window of low temperature chemistry [30]. In our previous study [19], however, a diffusion cool flame was observed at room temperature with ozone addition. The question to ask here is whether ozone addition can also initiate a premixed cool flame at room temperature.

Figures $7 \mathrm{a}$ and $7 \mathrm{~b}$ show the effect of ozone addition on the flame temperature and flame speed, respectively, of DME/(1-x) $\mathrm{O}_{2}+\mathrm{xO}_{3}$ mixtures at $1 \mathrm{~atm}$ and $300 \mathrm{~K}$. The ozone concentration in the oxidizer is increased from 0 to $8 \%(\mathrm{x}=0-0.08)$. Figure $7 \mathrm{a}$ shows that ozone addition significantly changes the dependence of flame temperature and flame regimes on equivalence ratio. Without ozone addition $(\mathrm{x}=0)$, as discussed before, the high temperature flame extinguishes at an equivalence ratio of $\Phi=0.0785$. However, with $2 \%$ ozone addition, it is seen that even at room temperature, a cool flame branch exists beyond the flammability limit of the HTF. Note that here the transition from the HTF to the cool flame is via an extinction transition (a turning point in the S-curve). As the ozone concentration is increased to $5 \%$, the existence of the cool flame is extended further to leaner conditions. It is interesting to note that at this condition the HTF directly transfers into a cool flame via a double flame structure (Fig. 4b) without an extinction limit. As the ozone concentration further increases, the direct transition to the cool flame shifts further to lower equivalence ratios via the double flame.

One may argue that the addition of ozone into the mixture modifies the initial mixture enthalpy and flame temperature. At equivalence ratio of $\Phi=0.1$, the change of the mixture enthalpy per unit mass with $5 \%$ ozone in the oxidizer stream is approximately equivalent to a $208 \mathrm{~K}$ rise in the unburned mixture. Therefore, the mixture enthalpy of the $5 \%$ ozone mixture at $300 \mathrm{~K}$ in Fig. $7 \mathrm{a}$ is equivalent to that of a $\mathrm{DME} / \mathrm{O}_{2}$ mixture at $508 \mathrm{~K}$. A direct comparison between the flame regime dependencies on equivalence ratio in Figs. $2 \mathrm{a}$ (the DME/ $\mathrm{O}_{2}$ mixture at $\left.530 \mathrm{~K}\right)$ and $7 \mathrm{a}(5 \%$ ozone mixture at $300 \mathrm{~K}$ ) show that even at a lower mixture enthalpy, ozone addition still further 
kinetically increases the flame reactivity and extends the formation of cool flame at a lower fuel concentration $(\Phi=0.06)$.

The dependence of flame speeds on ozone concentration is shown in Fig. 7b. It is seen that the transition from high temperature flames to cool flames for ozone concentrations of $2 \%$ and $5 \%$ does not lead to any large change in flame speed. Instead, the flame speeds of the HTF, the double flame, and the cool flame at the same equivalence ratio (say, $\Phi=0.075$ for $3 \% \mathrm{O}_{3}$ ) in the flame transition region have essentially no difference. Moreover, the cool flame speed increases with increases in ozone concentration. It is also interesting to note that the ozone-assisted cool flame speed $(5-15 \mathrm{~cm} / \mathrm{s})$ is much higher than the flame speeds of the HTF near the conventional flammability limit (1-2 cm/s) without ozone addition.

Therefore, ozone significantly enhances the low temperature chemistry, enables cool flame propagation at low temperatures, extends the transition limit from the HTF to the cool flame, and increases the propagation speed of cool flames. A sensitivity analysis of ozone-assisted cool flames shows that the following reaction pathway plays an important role in enhancing cool flame chemistry with ozone addition:

$$
\begin{aligned}
& \mathrm{O}_{3}+\mathrm{O}_{2}=2 \mathrm{O}_{2}+\mathrm{O} \\
& \mathrm{O}+\mathrm{CH}_{3} \mathrm{OCH}_{3}=\mathrm{CH}_{3} \mathrm{OCH}_{2}+\mathrm{OH} \\
& \mathrm{OH}+\mathrm{CH}_{3} \mathrm{OCH}_{3}=\mathrm{CH}_{3} \mathrm{OCH}_{2}+\mathrm{H}_{2} \mathrm{O} \\
& \mathrm{O}_{2}+\mathrm{CH}_{3} \mathrm{OCH}_{2}=\mathrm{O}_{2} \mathrm{CH}_{3} \mathrm{OCH}_{2} \\
& \mathrm{CH}_{3} \mathrm{OCH}_{2} \mathrm{O}_{2}=\mathrm{CH}_{2} \mathrm{OCH}_{2} \mathrm{O}_{2} \mathrm{H} \\
& \mathrm{CH}_{2} \mathrm{OCH}_{2} \mathrm{O}_{2} \mathrm{H}+\mathrm{O}_{2}=\mathrm{O}_{2} \mathrm{CH}_{2} \mathrm{OCH} \mathrm{O}_{2} \mathrm{H} \\
& \mathrm{O}_{2} \mathrm{CH}_{2} \mathrm{OCH}_{2} \mathrm{O}_{2} \mathrm{H}=\mathrm{HO}_{2} \mathrm{CH}_{2} \mathrm{OCHO}+\mathrm{OH} \\
& \mathrm{HO}_{2} \mathrm{CH}_{2} \mathrm{OCHO}=\mathrm{OCH}_{2} \mathrm{OCHO}+\mathrm{OH}
\end{aligned}
$$

Without ozone, reaction (2b) is the only chain propagation reaction to produce the initial $\mathrm{CH}_{3} \mathrm{OCH}_{2}$ radicals. With $\mathrm{O}_{2}$ addition to $\mathrm{CH}_{3} \mathrm{OCH}_{2}$ (3) and the subsequent isomerization (4), second $\mathrm{O}_{2}$ addition (5), and decomposition (6-7), two new $\mathrm{OH}$ radicals are produced and the chain-branching process accelerates. However, at low temperatures the $\mathrm{OH}$ concentration is very low and the initial chain propagation reaction $(2 \mathrm{~b})$ is very slow. Therefore, no cool flame is formed at $300 \mathrm{~K}$. However, with ozone addition, $\mathrm{O}$ is formed at low temperatures via ozone decomposition (1) in the preheating zone of the cool flame. As such, $\mathrm{H}$ abstraction from the fuel via reaction (2a) produces two radicals, which not only bypasses reaction (2b) in producing the $\mathrm{CH}_{3} \mathrm{OCH}_{2}$ radical but also doubles the initial radical production rate. As a result, the low temperature chemistry is greatly accelerated by ozone addition and the cool flame can be observed at $300 \mathrm{~K}$. Note that a typical plasma generator can produce more than $10 \%$ ozone in an oxygen stream at a very large 
flow rate. The above analysis shows that by either adding radicals into the system or ozone into the unburned mixture, a fast-propagating cool flame may be formed experimentally.

The above results further suggest that in turbulent combustion, either elevated temperatures or radical recirculation can create a propagating cool flame at a fuel concentration beyond the conventional flammability limit. Unfortunately, the existence of cool flames in engines is often ignored in today's experimental and numerical efforts for turbulent combustion and fire safety.

\subsection{Flame Regimes and Extinction Limits of Stretched Premixed Cool Flames}

In practical combustion, flames are usually stretched. In this section, we examine the effects of mixture temperature and ozone addition on the formation and dynamics of stretched cool flames in the counterflow configuration.

The computational geometry of the one-dimensional counterflow premixed flame with inert gas $\left(\mathrm{N}_{2}\right)$ is shown in Fig. 1b. The preheated nitrogen nozzle is located at $X=0 \mathrm{~cm}$ and the fuel nozzle is located at $X=2.25 \mathrm{~cm}$ or $1.5 \mathrm{~cm}$, respectively, for the high temperature flames and cool flames. The temperature of the inert gas in the opposing flow $\left(\mathrm{T}_{\mathrm{N} 2}\right)$ is varied from $450 \mathrm{~K}$ to $800 \mathrm{~K}$. A potential flow assumption is adopted. The governing equations of this flame system are described in detail in our previous study [33].

Fig. 8a shows the dependence of the maximum flame temperature on stretch rate for $\mathrm{T}_{\mathrm{N} 2}=$ $600 \mathrm{~K}$ and an unburned mixture temperature of $\mathrm{T}_{\text {Fuel }}=300 \mathrm{~K}$ with $5 \%$ ozone in the oxidizer. It is seen that with a decrease in stretch rate, low temperature ignition (LTI) occurs at stretch rate of $24.6 \mathrm{~s}^{-1}$ (point $d$ ). Note that at LTI, the temperature increase before ignition is very small. On the other hand, at higher temperatures, a HTF can be formed (the upper branch of Fig. 8a). As the stretch rate increases, the HTF extinguishes at stretch rate of $484 \mathrm{~s}^{-1}$, and no flame can exist beyond this stretch rate. Therefore, point $a$ in Fig. $8 \mathrm{a}$ is the extinction limit of the HTF and appears in the figure as a turning point. Both increases and decreases in the maximum flame temperature at point $a$ produce solutions at lower stretch rates. Between the HTF and LTI, there exists a region $(b c)$ in which a cool flame can be stabilized. The cool flame stability region is bounded by the high temperature ignition (HTI) limit (point $b, 180 \mathrm{~s}^{-1}$ ) and the cool flame extinction (CF ext.) limit (point $c, 230 \mathrm{~s}^{-1}$ ). Therefore, with ozone addition, it is possible to stabilize a cool flame even at stretch rates as high as $200 \mathrm{~s}^{-1}$, that is, a residence time of $5 \mathrm{~ms}$.

The effect of the inert gas temperature on the flammable region of cool flames is shown in Fig. 8b. As the nitrogen temperature decreases from $600 \mathrm{~K}$ to $450 \mathrm{~K}$, it is seen that both the LTI limit and the cool flame region move to lower stretch rates. The transition to the cool flame from 
the unburned mixture remains an ignition transition, and the stretch rate window of stable cool flames shrinks slightly. Additionally, the decrease in inert temperature has little impact on the extinction limit of the HTF because the temperature change in the nitrogen flow affects neither the chemistry nor the heat loss so drastically that it changes the HTF.

However, when the inert gas temperature is increased to $800 \mathrm{~K}$, it is seen that both the extinction limits of the HTF and the cool flame shift to higher stretch rates. Furthermore, it is interesting to note that there is no ignition limit of LTI. Instead, as the stretch rate decreases, the unburned mixture directly transfers to a cool flame without ignition occurring. This direct transition to the cool flame may allow for easier observation of cool flame in experiments. Moreover, the cool flame region $(a b)$ is significantly broadened with the increase in the inert gas temperature to $800 \mathrm{~K}$.

Therefore, with ozone addition, a premixed cool flame can be observed at high stretch rates. In addition, depending on the inert gas temperature, there are two different types of transitions to cool flames - an ignition transition at lower inert gas temperatures and a direct transition at higher temperatures. The above findings not only provide a global picture of cool flame dynamics but also offer likely conditions for experimental observation of premixed cool flames using ozone sensitization in a counterflow experiment. Preliminary experiments that have captured some of the dynamics of ozone-assisted DME premixed cool flames can be seen in [35]. More recently, preliminary observation of DME cool flames without ozone was also reported in [36]. Nevertheless, quantitative comparison between experiments and modeling need to be conducted in the future.

In order to understand whether a premixed cool flame can be observed without ozone addition, the flame regimes and dynamics of the DME/oxygen mixture are also computed in the counterflow configuration. Moreover, to understand the kinetic effect of ozone on cool flame formation at the same enthalpy, the initial temperature of the $\mathrm{DME} / \mathrm{O}_{2}$ mixture is increased to 508 $\mathrm{K}$ so that the $\mathrm{DME} / \mathrm{O}_{2}$ mixture and the $\mathrm{DME} / 0.95 \mathrm{O}_{2}+0.05 \mathrm{O}_{3}$ mixture at $300 \mathrm{~K}$ have the same enthalpy of $-12.9 \mathrm{~kJ} / \mathrm{kg}$ at equivalence ratio of 0.122 . Fig. 9a shows a comparison of the flame temperatures of the two mixtures as a function of stretch rate. It is seen that even without ozone, the cool flame still exists for stretched flames. Compared to the ozone-sensitized cool flame, the cool flame without ozone addition exists in a slightly broader range of stretch rates but at much lower stretch rates (longer residence times). Therefore, the enhancement of cool flame formation at higher stretch rates by ozone addition is not caused by the increase of the mixture thermal enthalpy; rather, it is due to the kinetic enhancement of accelerating the radical branching processes at low temperatures. Ozone addition also extends the cool flame extinction limit to a much higher 
stretch rate $\left(230 \mathrm{~s}^{-1}\right)$. Moreover, the high temperature ignition (HTI) also occurs at a higher stretch rate.

Finally, the dependence of the location of the cool flame front (indicated by the maximum heat release rate) on stretch rate for the $\mathrm{DME} / \mathrm{O}_{2}$ cool flame is shown in Fig. 9b. It seen that before LTI, the reaction zone is located on the preheated nitrogen flow side of the stagnation plane (X $=$ $0.75 \mathrm{~cm}$ ). Once the cool flame is formed, the cool flame front moves to the fuel side of the stagnation plane. The decreasing temperature dependence of cool flame on stretch rate suggests that cool flame has a positive flame stretch. As the stretch rate decreases, the cool flame front moves further upstream towards the fuel nozzle. On the other hand, with an increase in stretch rate, the cool flame front moves towards the stagnation plane $(X=0.75 \mathrm{~cm})$ and extinguishes due to stretch effects at a location $(\mathrm{X}=0.83 \mathrm{~cm})$ that is a finite distance from the stagnation plane. The extinction of the counterflow flame at a finite distance from the stagnation plane confirms that the DME/oxygen cool flame has a Lewis number $(\mathrm{Le}=\alpha / \mathrm{D})$ larger than unity (stretch extinction). For mixtures with Lewis numbers less than or equal to unity, the flame would quench at the stagnation plane by incomplete combustion. This result is consistent with the predicted flame speeds of cool flames and the flame speed sensitivity on species diffusivity in Figs. 2 and $6 \mathrm{~b}$.

\section{Conclusion}

The formation and dynamics of premixed cool flames of dimethyl-ether mixtures in both freely-propagating and stretched counterflow flames are numerically modeled with and without ozone sensitization. The following conclusions are obtained.

For freely propagation flames, three different flame regimes-high temperature flames, double structured flames, and cool flames - are predicted at elevated mixture temperatures. The results show that the flammability limit of dimethyl ether flames is significantly extended by the presence of cool flames and that the conventional concept of the flammability limit of a high temperature flame needs to be reconsidered. Moreover, the results demonstrate that the propagation speed of cool flames can be significantly higher than that of near-limit high temperature flames. A schematic of a modified flammability limit diagram including both high temperature flames and cool flames is proposed.

With ozone addition, the kinetic enhancement of low temperature fuel oxidation enables cool flame formation at room temperature. The results show that ozone addition dramatically promotes the formation of cool flames at low mixture temperatures, extends the transition of high temperature flames to cool flames to lower equivalence ratios, increases the cool flame speed, and extends the flammability limit. 
For stretched counterflow flames, the results also show that stretched cool flames can exist with and without ozone addition by a preheated nitrogen flow. Ozone addition extends the cool flame formation window to higher stretch rates. Moreover, increases in the inert gas temperature also extend the formation of cool flames to higher stretch rates. Furthermore, two different cool flame transition regimes, a low temperature ignition transition and a direct transition, are predicted at low and high mixture temperatures, respectively. The results also show that the DME/oxygen cool flame has a Lewis number larger than unity and extinguishes at a finite distance from the stagnation plane.

The present results suggest that cool flames can be an important combustion process in affecting flammability limits and turbulent flames as the mixture temperature, turbulent mixing, and radical production/recirculation are increased. The results also provide guidance in observe self-sustaining premixed cool flames in future experiments.

While this study has provided much new knowledge of cool flames, not all questions, especially those concerning cool flame instability and the validity of the cool flame chemistry, have been answered. Future studies should address cool flame instability and make direct comparisons of the flame structure and dynamics between experiments and numerical modeling.

\section{Acknowledgments}

This work is supported by the NASA research grant NNX15AB67G and the NSF grants CMMI-1449314 and CBET-1507358.

\section{References}

[1] P.G. Lignola, E. Reverchon, Prog. Energy Combust. Sci. 13 (1987) 75-96.

[2] G. M. Rassweiler, L. Withrow, Ind. Eng. Chem. 28 (6) (1936) 672-677.

[3] J. E. Dec, Proc. Combust. Inst. 32 (2009) 2727-2742.

[4] W. Sun, S. H. Won, X. Gou, Y. Ju, Proc. Combust. Inst. 35 (2015) 1049-1056.

[5] P. Dai, Z. Chen, S. Chen, Y. Ju, Proc. Combust. Inst. 35 (2015) 3045-3052.

[6] V. Nayagam, D. L. Dietrich, P. V. Ferkul, M. C. Hicks, F. A. Williams, Combust. Flame 159 (2012) 3583-3588.

[7] H. Davy, Phil. T. Roy. Soc. 107 (1817) 77-82.

[8] W. H. Perkin, J. Chem. Soc. 41 (1882) 363-367.

[9] H. J. Emeleus, J. Chem. Soc. 129 (1926) 2948-2951.

[10] J. A. Powling, Fuel 28 (1949) 25.

[11] P. R. Ballinger, P. R. Ryason, Symp. (Int.) Combust. Proc. 13 (1971) 271-277.

[12] R. N. Pease, Chem. Rev. 21 (2) (1937) 279-286.

[13] D. T. A. Townend, Chem, Rev. 21 (2) (1937) 259-278. 
[14] J. F. Griffiths, T. Inomata, J. Chem. Soc. Faraday Trans. 88 (21) (1992) 3153-3158.

[15] L. R. Cairnie, A. J. Harrison, P. A. Morgan, Symp. (Int.) Combust. Proc. 18 (1981)17991806.

[16] H. Oshibe, H. Nakamura, T. Tezuka, S. Hasegawa, K. Maruta, Combust. Flame 157 (2010) 1572-1580.

[17] S. Kikui, T. Kamada, H. Nakamura, T. Tezuka, S. Hasegawa, K. Maruta, Proc. Combust. Inst. 35 (2015) 3405-3412.

[18] W. S. Affleck, A. Fish, Combust. Flame 12 (1968) 243-252.

[19] S. H. Won, B. Jiang, P. Diévart, C. H. Sohn, Y. Ju, Proc. Combust. Inst. 35 (2015) 881-888.

[20] http://science.nasa.gov/science-news/science-at-nasa/2013/18jun_strangeflames/

[21] T. I. Farouk, M. C. Hicks, F. L. Dryer, Proc. Combust.Inst. 35 (2015) 1701-1708.

[22] W. Sun, S. H. Won, Y. Ju, Combust. Flame 161 (2014) 2054-2063.

[23] Y. Ju, W. Sun, Prog. Energy Combust. Sci. 48 (2015) 21-83.

[24] Y. Ju, K. Maruta, T. Niioka, Appl. Mech. Rev. 54 (3) (2001) 257-277.

[25] P. Zhao, C. K. Law, Combust. Flame 160 (2013) 2352-2358.

[26] Y. Ju, W. Sun, M. P. Burke, X. Gou, Z. Chen, Proc. Combust. Inst. 33 (2011) 1245-1251.

[27] S. H. Won, B. Windom, B. Jiang, Y. Ju, Combust. Flame 161 (2014) 475-483.

[28] F. Herrmann, B. Jochim, P. Oßwald, L. Cai, H. Pitsch, K. Kohse-Höinghaus, Combust. Flame 161 (2014) 384-397.

[29] D. Liu, J. Santner, C. Togbé, D. Felsmann, J. Koppmann, A. Lackner, X. Yang, X. Shen, Y. Ju, K. Kohse-Höinghaus, Combust. Flame 160 (2013) 2654-2668.

[30] N. Kurimoto, B. Brumfield, X. Yang, T. Wada, P. Diévart, G. Wysocki, Y. Ju, Proc. Combust. Inst. 35 (2015) 457-464.

[31] Z. Zhao, M. Chaos, A. Kazakov, F. L. Dryer, Int. J. Chem. Kinet. 40 (1) (2008) 1-18.

[32] T. Ombrello, S. H. Won, Y. Ju, S. Williams, Combust. Flame 157 (2010) 1906-1915.

[33] Y. Ju, H. Guo, K. Maruta, F. Liu, J. Fluid Mech. 342 (1997) 315-334.

[34] R. J. Kee, J. F. Grcar, M. D. Smooke, J. A. Miller, “A Fortran Program for Modeling Steady Laminar One-Dimensional Premixed Flames," Sandia National Laboratories Report SAND85-8240 (1985).

[35] C. B. Reuter, S. H. Won, Y. Ju, "Cool Flames Activated by Ozone Addition," 53 ${ }^{\text {rd }}$ AIAA Aero. Sci. Meeting (2015), Kissimmee, FL, doi: 10.2514/6.2015-1387.

[36] P. Zhao, W. Liang, S. Deng, C. K. Law, "Ignition and Propagation of Laminar Premixed Cool Flames," submitted to Combust. Flame (2015).

[37] M. Foster, H. Pearlman, Combust. Sci. Tech. 179 (2007) 1349-1360. 


\section{Figure captions}

Fig.1 (a) Schematic of freely propagation flame and (b) schematic of nitrogen stabilized premixed counterflow flame for $\mathrm{DME} /(1-x) \mathrm{O} 2+x \mathrm{O} 3$ mixtures.

Fig.2 (a) Dependence of flame temperature on equivalence ratio for $\mathrm{DME} / \mathrm{O}_{2}$ freely propagating premixed flames at unburned mixture temperatures of $300 \mathrm{~K}$ and $530 \mathrm{~K}$, respectively.

Fig.2 (b) Dependence of flame speed on equivalence ratio for $\mathrm{DME} / \mathrm{O}_{2}$ freely propagating premixed flames at unburned mixture temperatures of $300 \mathrm{~K}$ and $530 \mathrm{~K}$, respectively.

Fig.2 (c) Dependence of flame speed on equivalence ratio for $\mathrm{DME} / \mathrm{O}_{2}$ freely propagating premixed flames at unburned mixture temperatures of $300 \mathrm{~K}, 400 \mathrm{~K}$, and $530 \mathrm{~K}$, respectively on fuel rich side.

Fig.3 Schematic of the flammable regions and flammability limits of high temperature flames and cool flames of $\mathrm{DME} / \mathrm{O}_{2}$ mixtures at $530 \mathrm{~K}$ by using the dependence of flame temperature as a function of equivalence ratio. $\Phi_{0, \mathrm{C}}$ : the lean flammability limit of the cool flame, $\Phi_{0}$ : the lean flammability limit of the high temperature flame (the conventional flammability limit).

Fig.4 (a) The distributions of temperature and species concentrations of DME/oxygen high temperature flame at equivalence ratio of 0.1 and temperature of $530 \mathrm{~K}$.

Fig.4 (b) The distributions of temperature and species concentrations of DME/oxygen double flame at mixture equivalence ratio of 0.1 and temperature of $530 \mathrm{~K}$.

Fig.4 (c) The distributions of temperature and species concentrations of DME/oxygen cool flame at mixture equivalence ratio of 0.1 and temperature of $530 \mathrm{~K}$.

Fig.5 The comparison of volumetric conductive heat transfer rate and chemical heat release rate for (a) high temperature flame, (b) double flame, and (c) cool flame for $\mathrm{DME} / \mathrm{O}_{2}$ mixtures at an initial temperature of $530 \mathrm{~K}$.

Fig.6a The normalized flame speed sensitivities to the reaction rates for the cool flame at mixture equivalence ratio of 0.1 and temperature of $530 \mathrm{~K}$.

Fig.6b The normalized flame speed sensitivities to the mixture averaged mass diffusivity for both high temperature flame and cool flame at mixture equivalence ratio of 0.1 and temperature of $530 \mathrm{~K}$.

Fig.7 (a) Dependence of flame temperature on equivalence ratio for DME/(1-x) $\mathrm{O}_{2}+\mathrm{xO}_{3}$ flames with difference percentages of $\mathrm{O}_{3}$ addition $(\mathrm{x}=0,0.02,0.05$, and 0.08$)$ at unburned mixture temperatures of $300 \mathrm{~K}$.

Fig.7 (b) Dependence of flame speed on equivalence ratio for $\mathrm{DME} /(1-\mathrm{x}) \mathrm{O}_{2}+\mathrm{xO}_{3}$ flames with difference percentages of $\mathrm{O}_{3}$ addition $(\mathrm{x}=0,0.02,0.05$, and 0.08$)$ at unburned mixture temperatures of $300 \mathrm{~K}$. 
Fig.8 (a) Dependence of flame temperature on stretch for $\mathrm{DME} / 0.95 \mathrm{O}_{2}+0.05 \mathrm{O}_{3}$ counterflow flames at equivalence ratio of 0.122 , unburned mixture temperatures of $300 \mathrm{~K}$, and nitrogen temperature of $600 \mathrm{~K}$.

Fig.8 (b) Comparison of the dependences of flame temperature on stretch for DME $/ 0.95 \mathrm{O}_{2}+$ $0.05 \mathrm{O}_{3}$ counterflow flames at equivalence ratio of 0.122 and unburned mixture temperatures of $300 \mathrm{~K}$ for different nitrogen flow temperature $(450-800 \mathrm{~K})$.

Fig.9 (a) Dependence of flame temperature on stretch for DME/O $\mathrm{O}_{2}$ counterflow flames at equivalence ratio of 0.122 , unburned mixture temperatures of $508 \mathrm{~K}$, and nitrogen temperature of $600 \mathrm{~K}$.

Fig.9 (b) Dependence of the location of cool flame on stretch rate for $\mathrm{DME} / \mathrm{O}_{2}$ counterflow flames at equivalence ratio of 0.122 , unburned mixture temperatures of $508 \mathrm{~K}$, and nitrogen temperature of $600 \mathrm{~K}$. The stagnation plane is located at $\mathrm{X}=0.75 \mathrm{~cm}$.

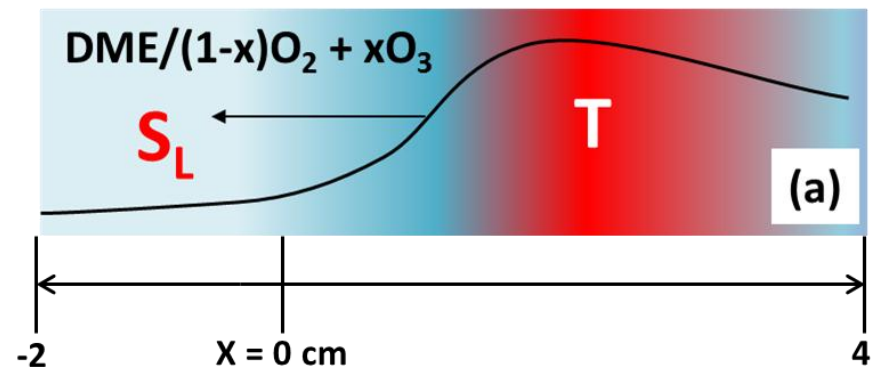




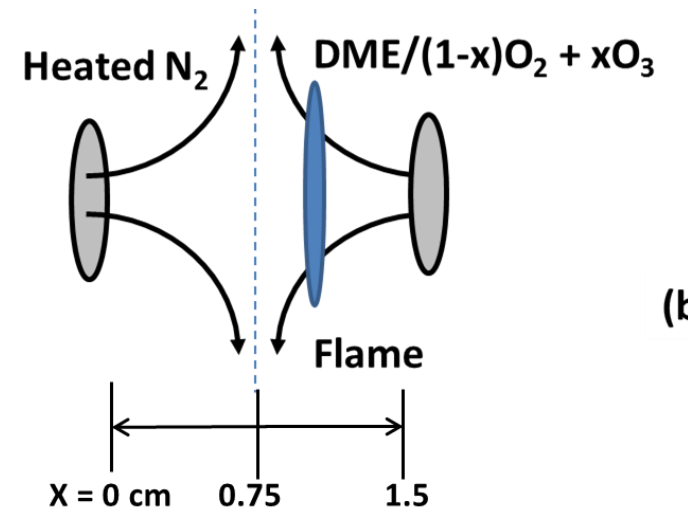

(b)

Fig. 1 (a) Schematic of freely propagation flame and (b) schematic of nitrogen stabilized premixed counterflow flame for DME/ $(1-x) \mathrm{O} 2+x \mathrm{O} 3$ mixtures.

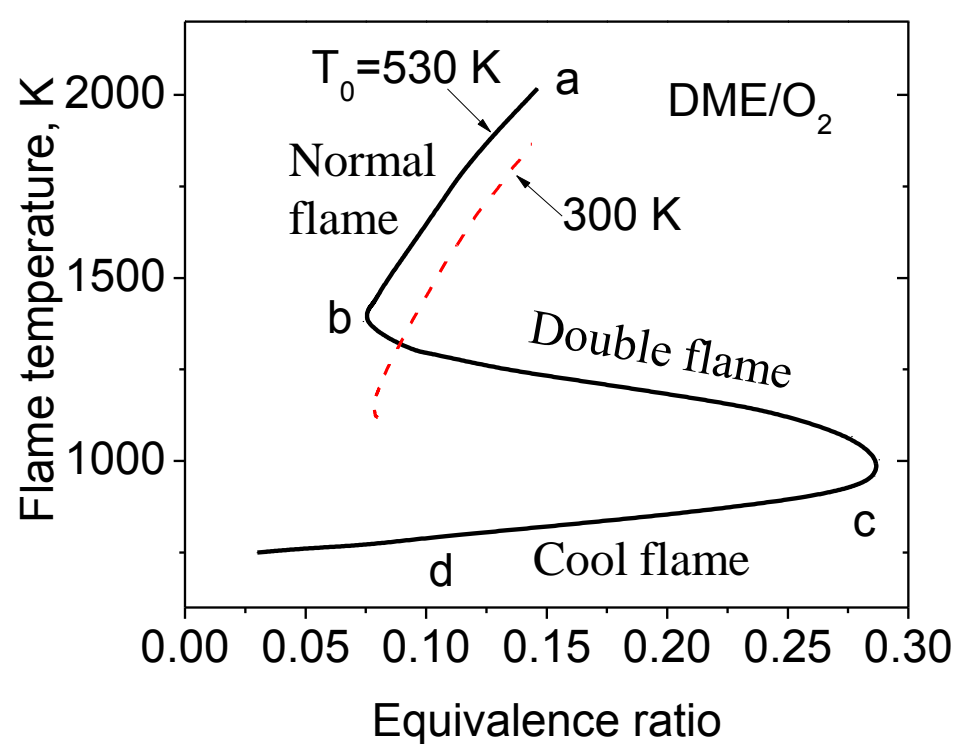

(a)

Fig. 2a Dependence of flame temperature on equivalence ratio for $\mathrm{DME} / \mathrm{O}_{2}$ freely propagating premixed flames at unburned mixture temperatures of $300 \mathrm{~K}$ and $530 \mathrm{~K}$, respectively. 


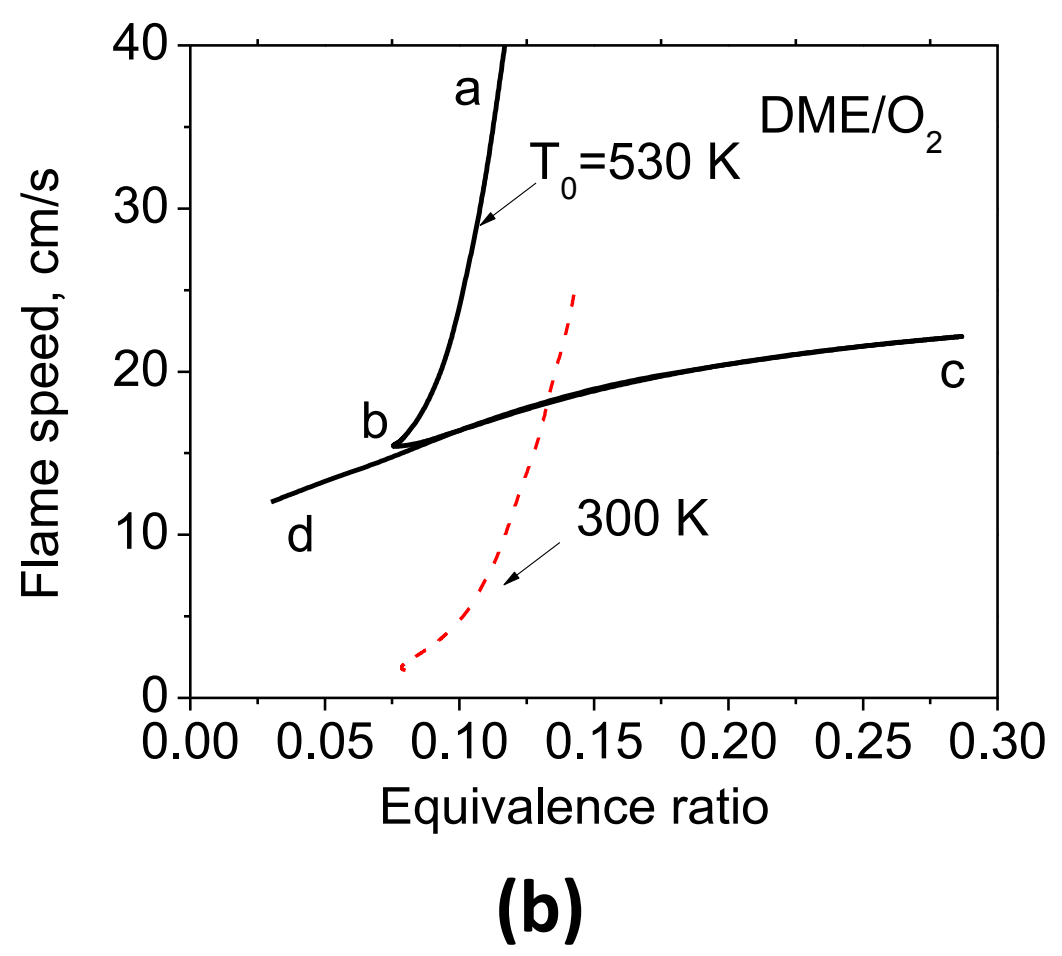

Fig. 2b Dependence of flame speed on equivalence ratio for $\mathrm{DME} / \mathrm{O}_{2}$ freely propagating premixed flames at unburned mixture temperatures of $300 \mathrm{~K}$ and $530 \mathrm{~K}$, respectively.

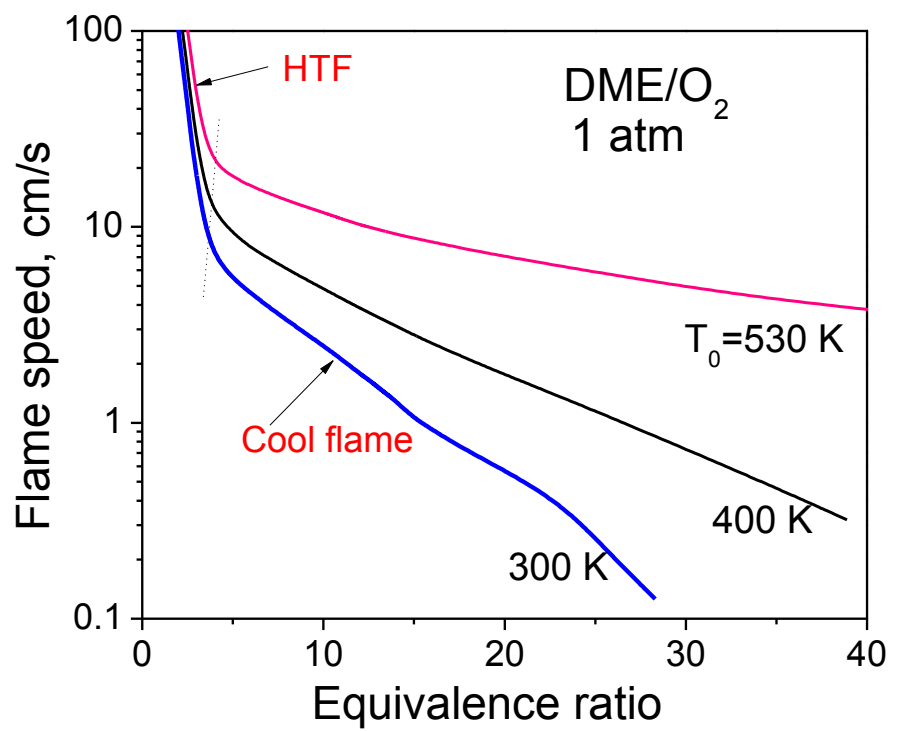

Fig. 2c Dependence of flame speed on equivalence ratio for $\mathrm{DME} / \mathrm{O}_{2}$ freely propagating premixed flames at unburned mixture temperatures of $300 \mathrm{~K}, 400 \mathrm{~K}$, and $530 \mathrm{~K}$, respectively on fuel rich side. 


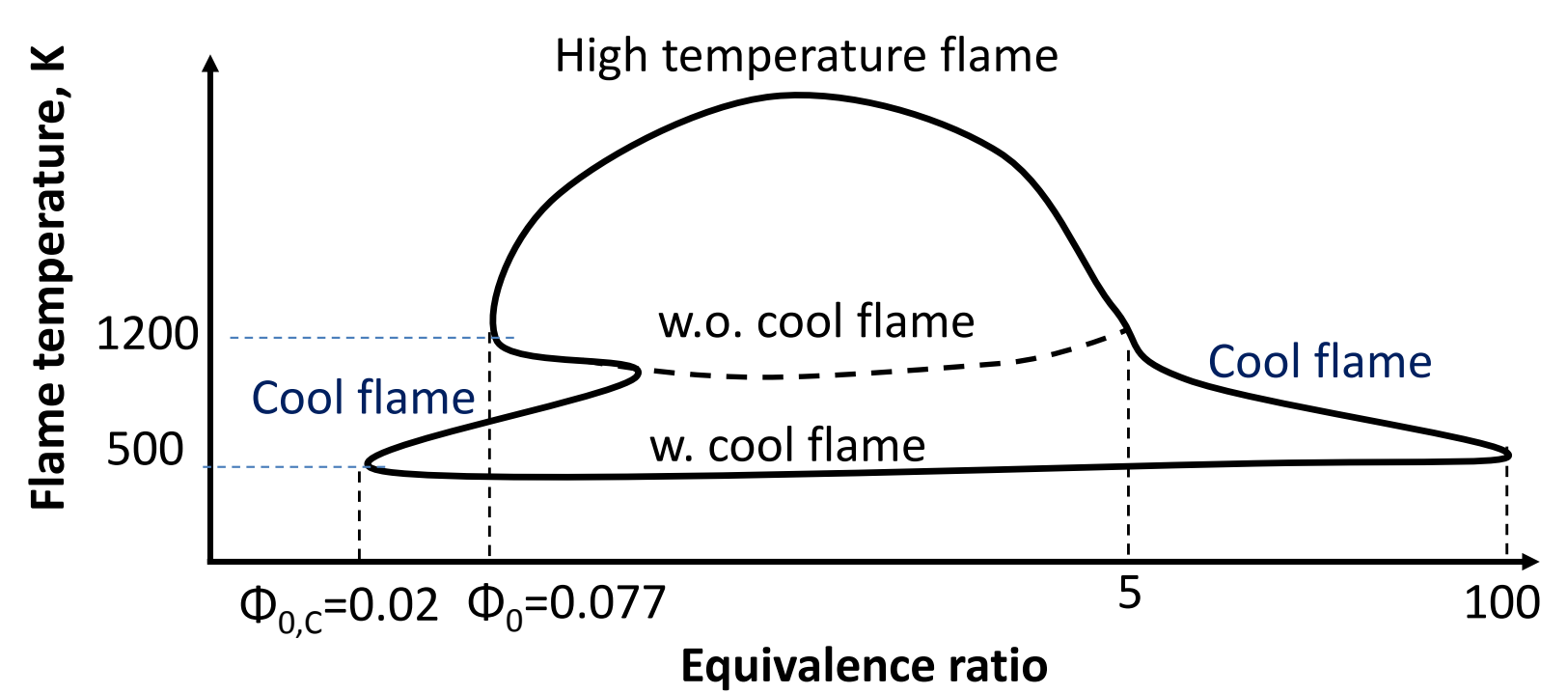

Fig. 3 Schematic of the flammable regions and flammability limits of high temperature flames and cool flames of $\mathrm{DME} / \mathrm{O}_{2}$ mixtures at $530 \mathrm{~K}$ by using the dependence of flame temperature as a function of equivalence ratio. $\Phi_{0, \mathrm{C}}$ : the lean flammability limit of the cool flame, $\Phi_{0}$ : the lean flammability limit of the high temperature flame (the conventional flammability limit). 

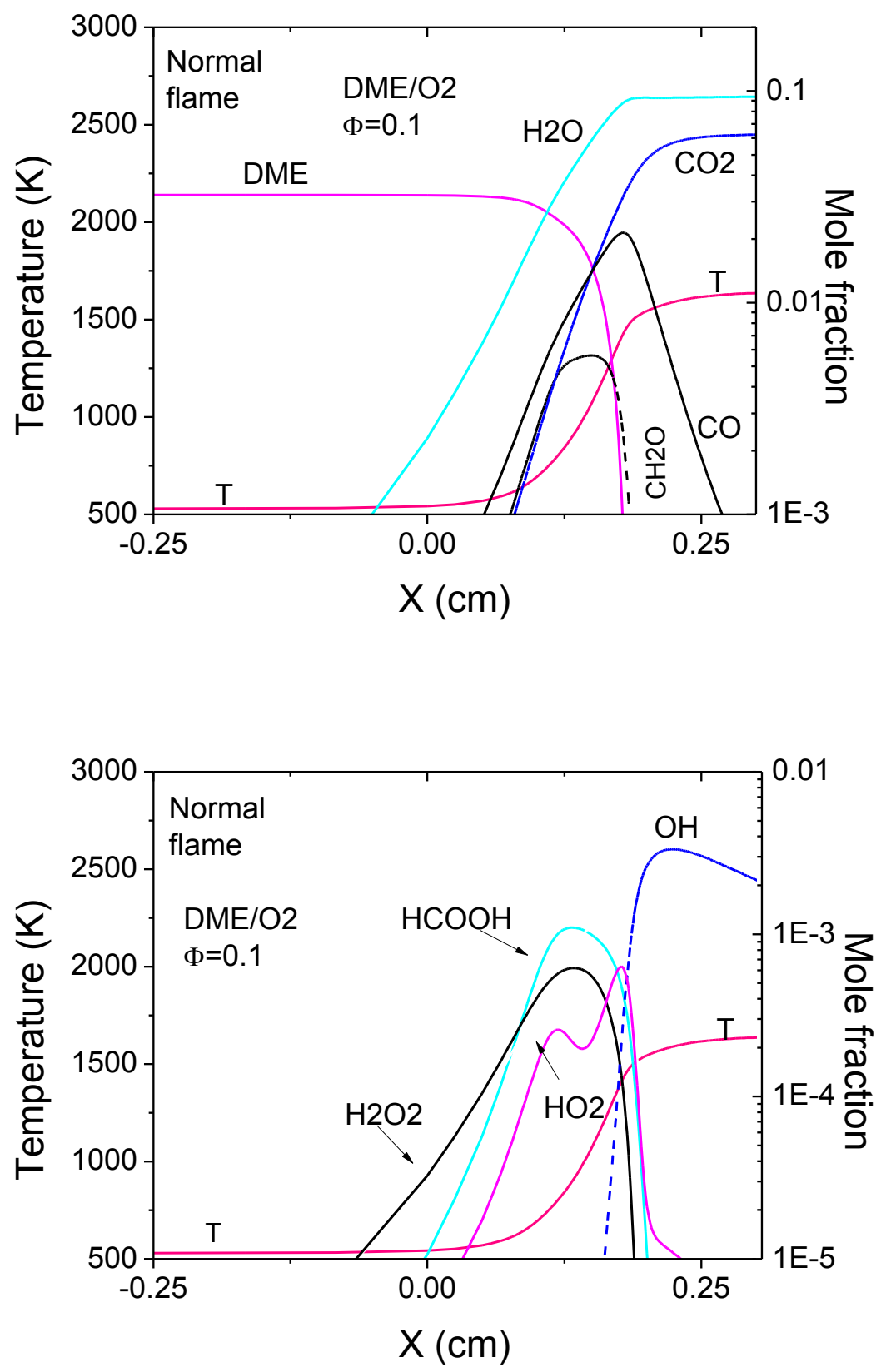

Fig. 4a The distributions of temperature and species concentrations of DME/oxygen high temperature flame at equivalence ratio of 0.1 and temperature of $530 \mathrm{~K}$. 

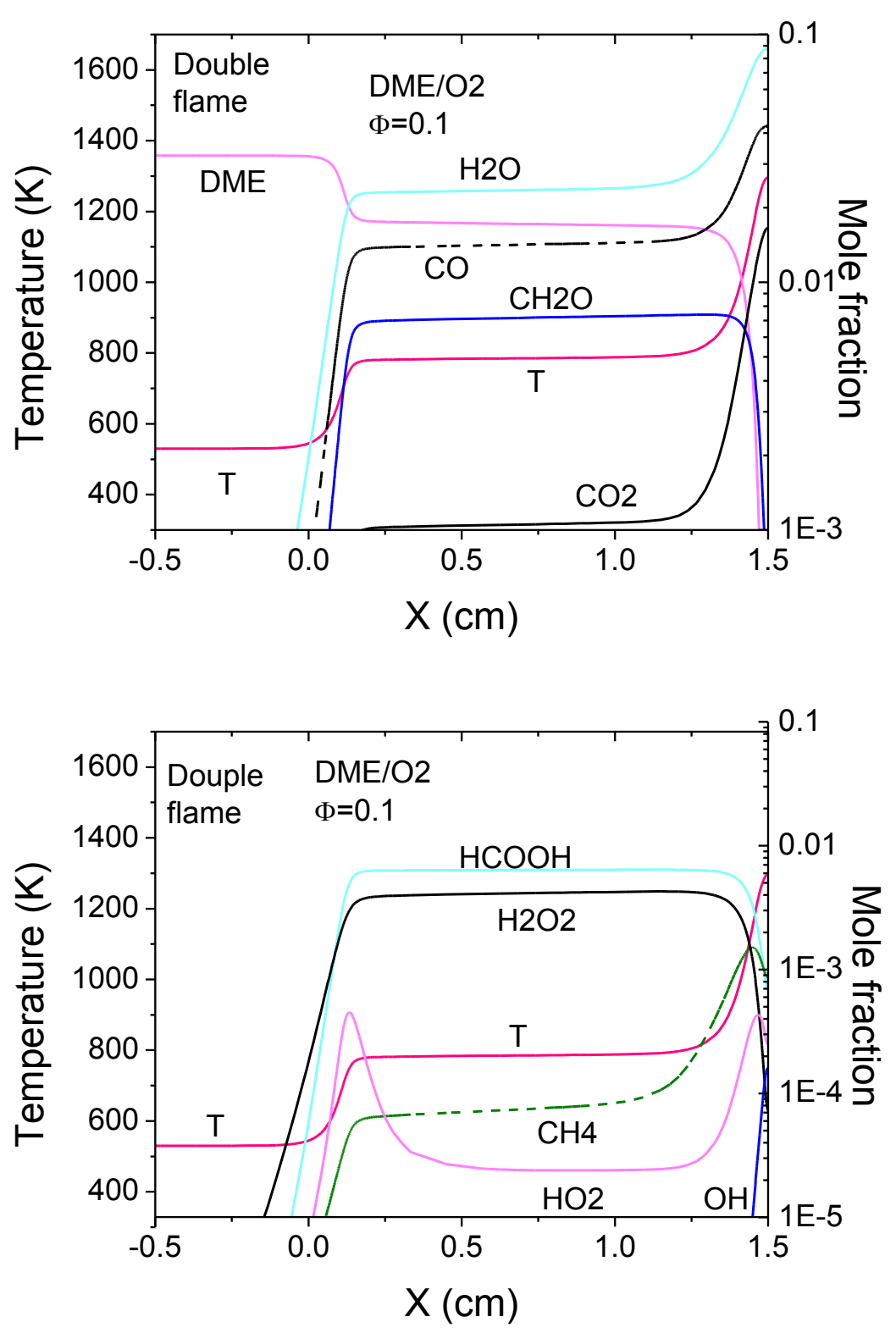

Fig. $4 \mathrm{~b}$ The distributions of temperature and species concentrations of DME/oxygen double flame at mixture equivalence ratio of 0.1 and temperature of $530 \mathrm{~K}$. 

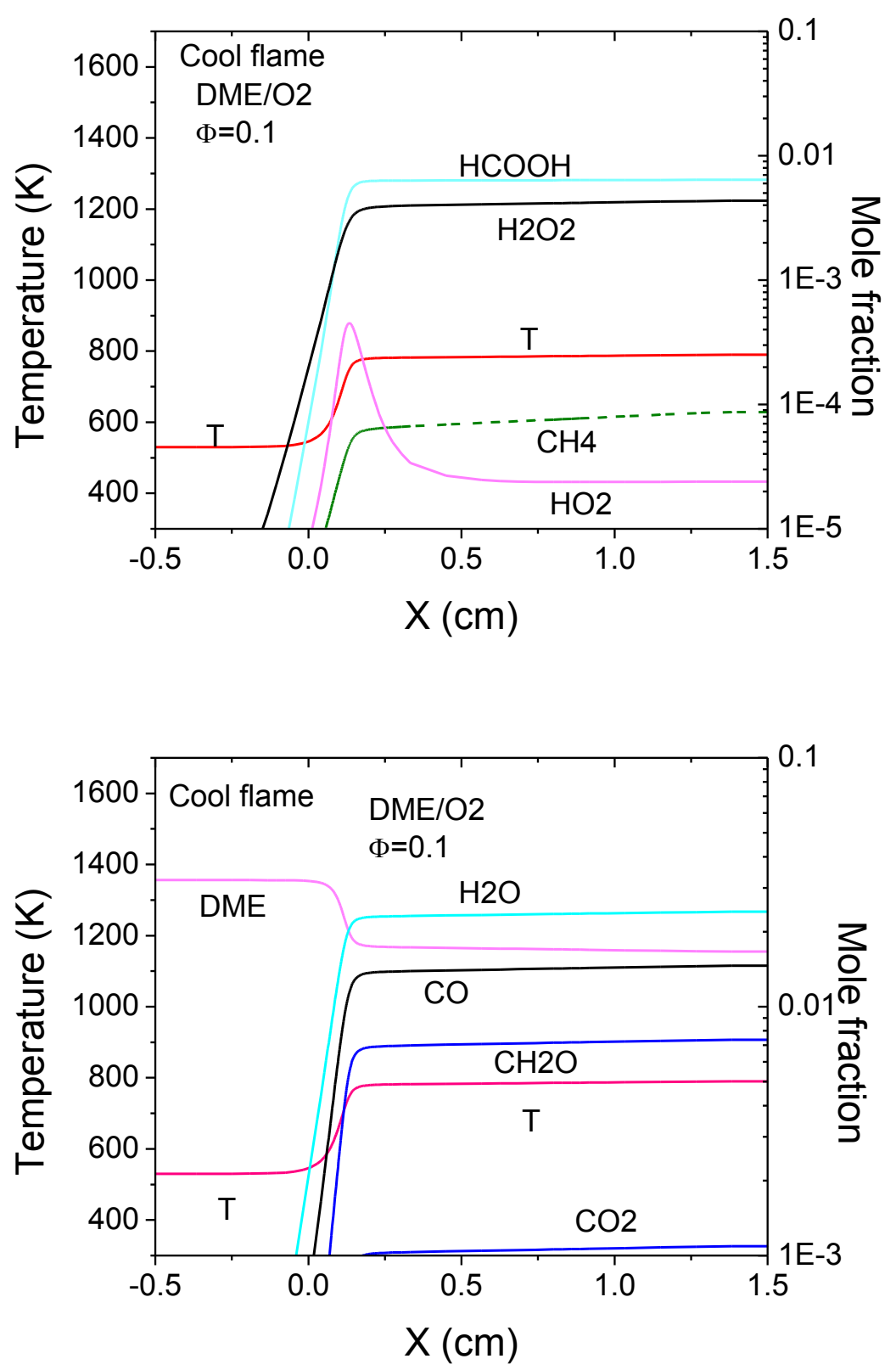

Fig. 4c The distributions of temperature and species concentrations of DME/oxygen cool flame at mixture equivalence ratio of 0.1 and temperature of $530 \mathrm{~K}$. 


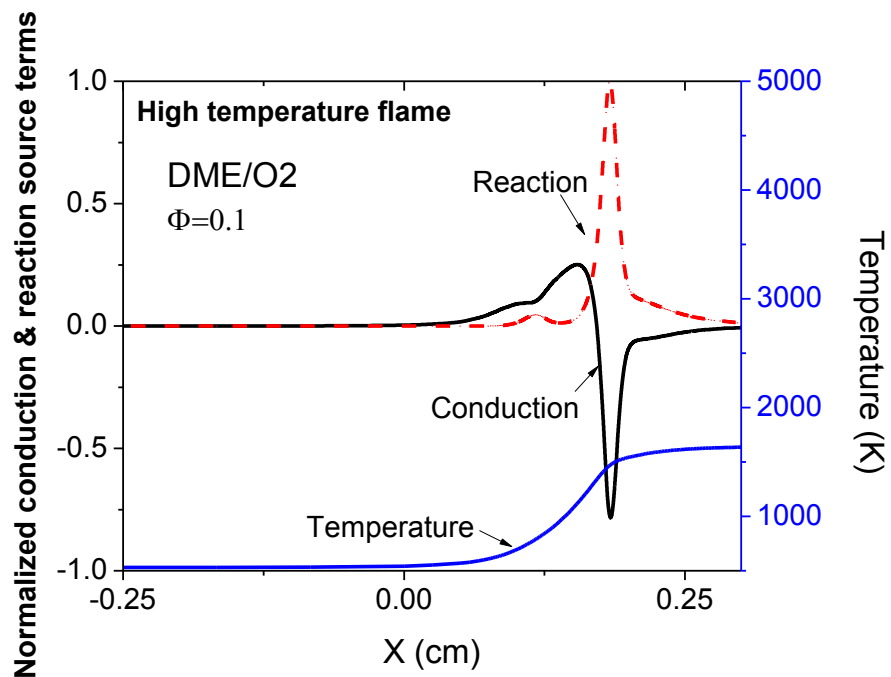

(a)

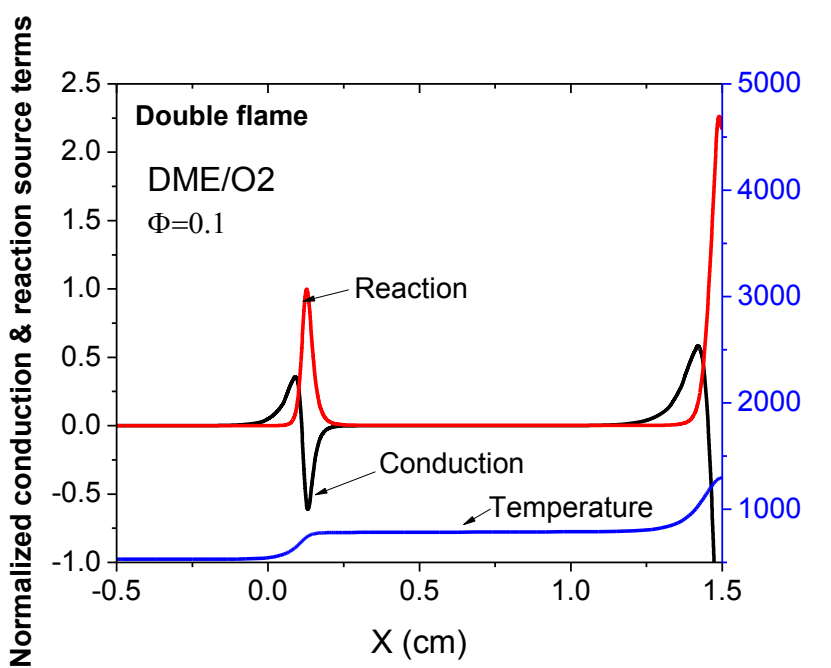

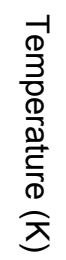

(b)

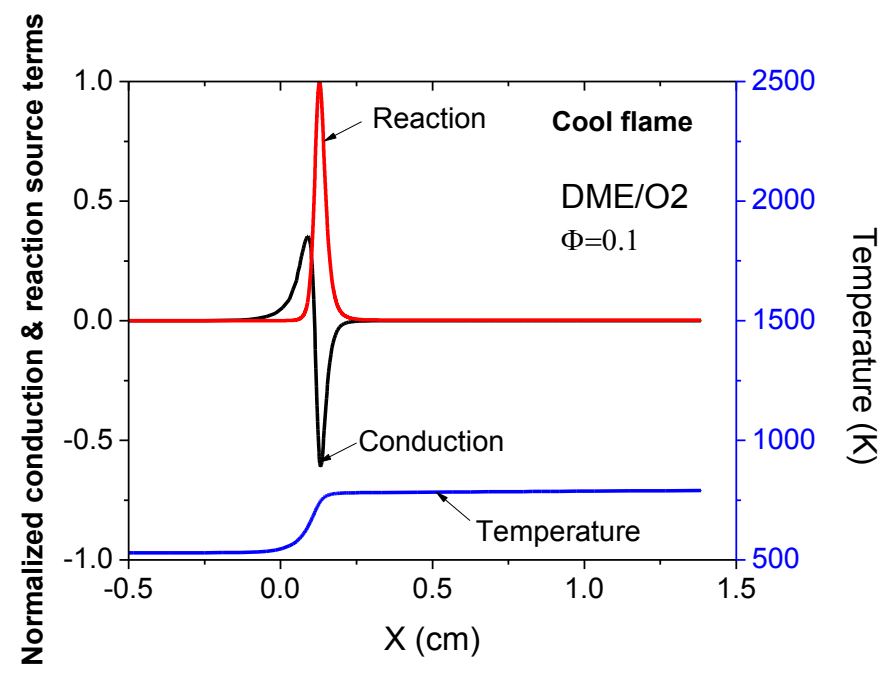

(c) 
Fig. 5 The comparison of volumetric conductive heat transfer rate and chemical heat release rate for (a) high temperature flame, (b) double flame, and (c) cool flame for $\mathrm{DME} / \mathrm{O}_{2}$ mixtures at an initial temperature of $530 \mathrm{~K}$. 


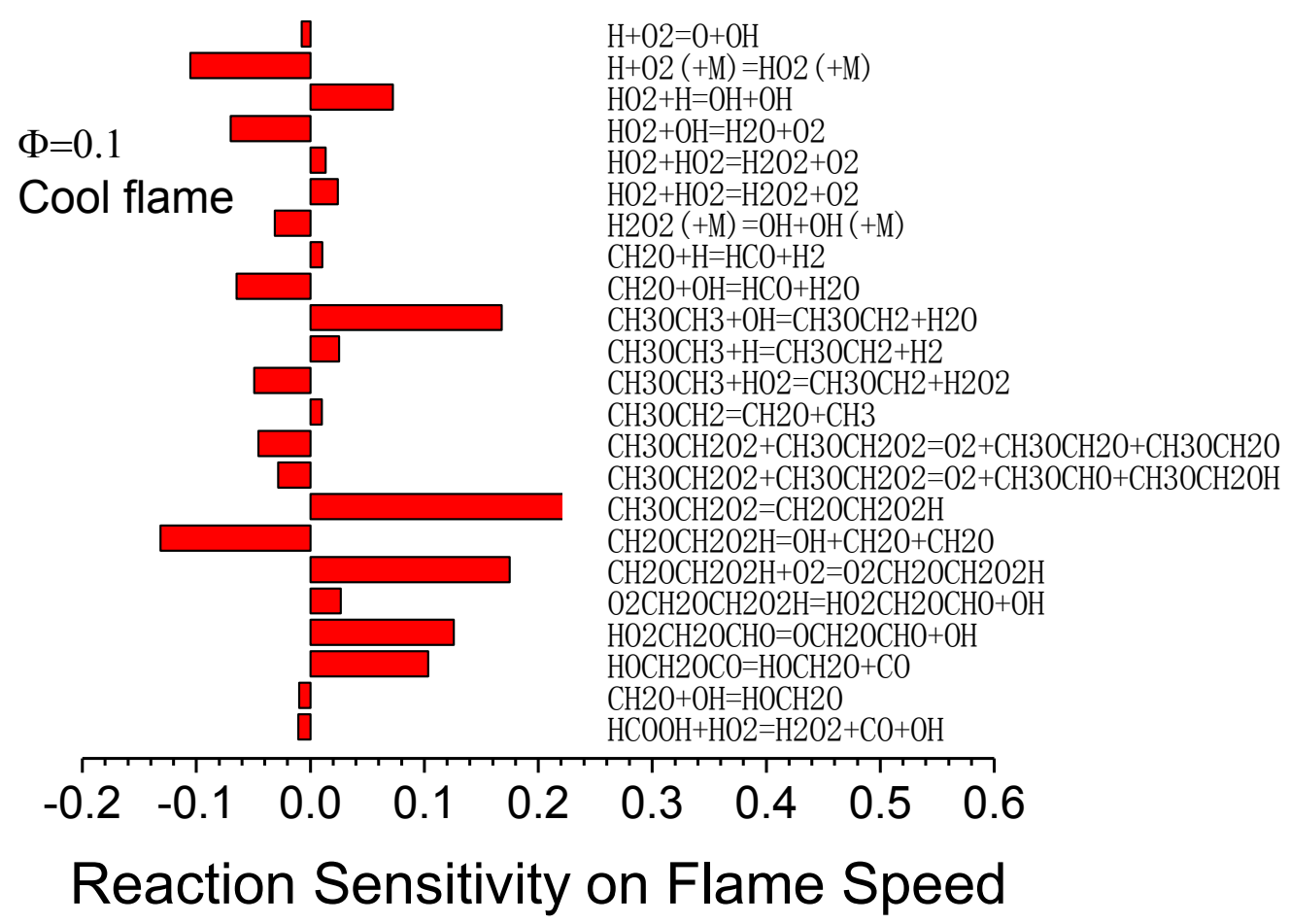

Fig. 6a The normalized flame speed sensitivities to the reaction rates for the cool flame at mixture equivalence ratio of 0.1 and temperature of $530 \mathrm{~K}$.

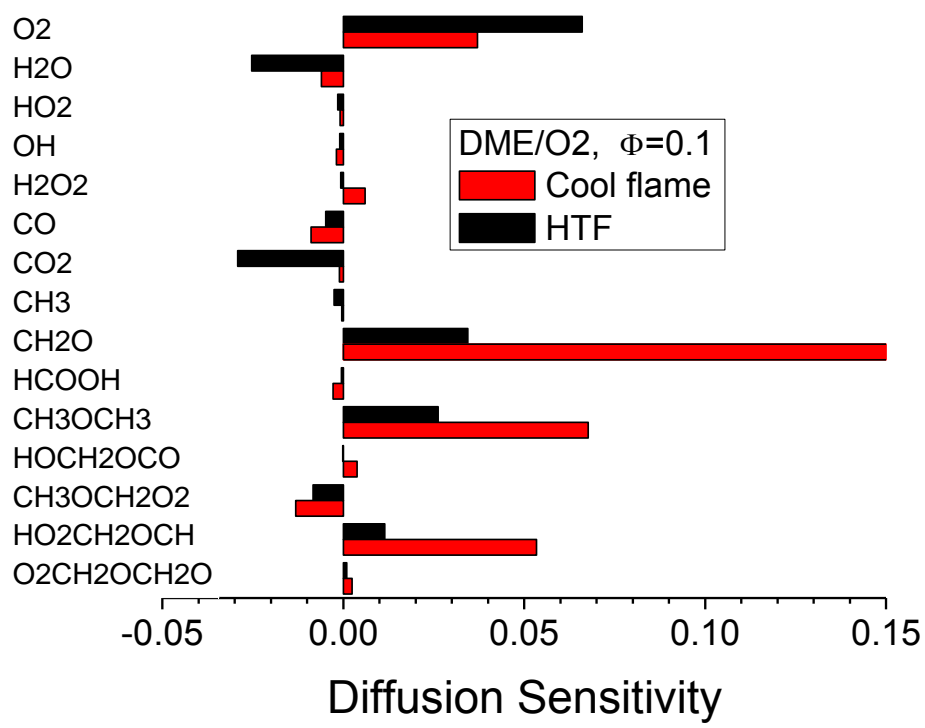

Fig. 6b The normalized flame speed sensitivities to the mixture averaged mass diffusivity for both high temperature flame and cool flame at mixture equivalence ratio of 0.1 and temperature of $530 \mathrm{~K}$. 


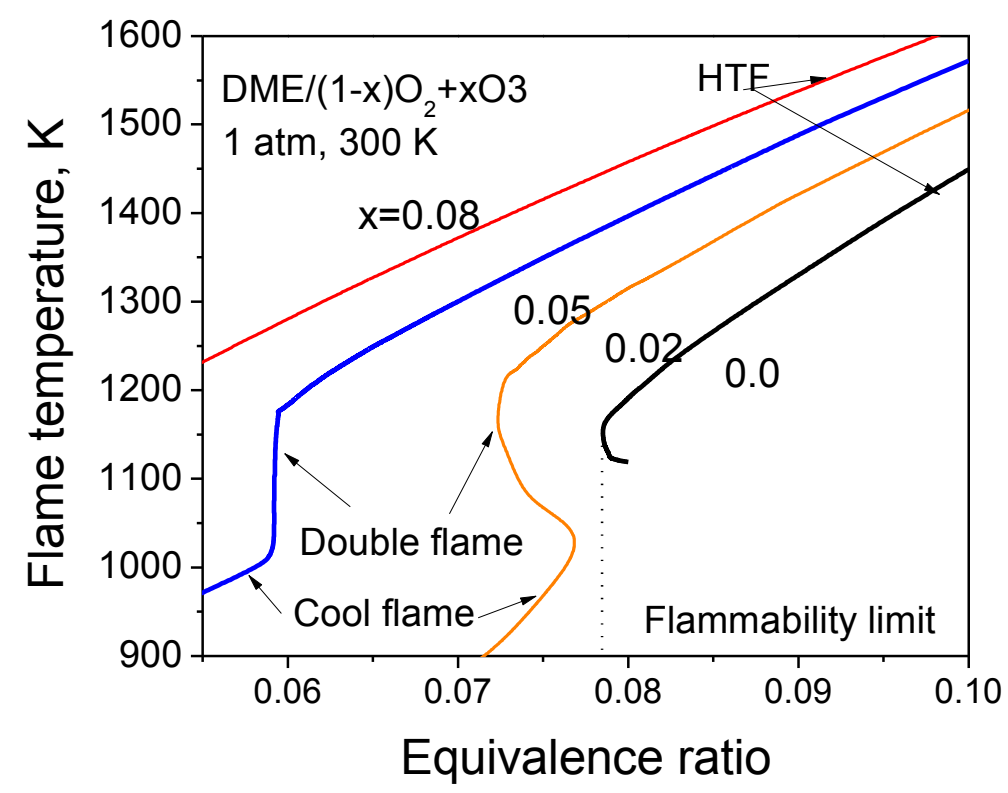

Fig. 7a Dependence of flame temperature on equivalence ratio for $\mathrm{DME} /(1-\mathrm{x}) \mathrm{O}_{2}+\mathrm{xO}_{3}$ flames with difference percentages of $\mathrm{O}_{3}$ addition $(\mathrm{x}=0,0.02,0.05$, and 0.08) at unburned mixture temperatures of $300 \mathrm{~K}$.

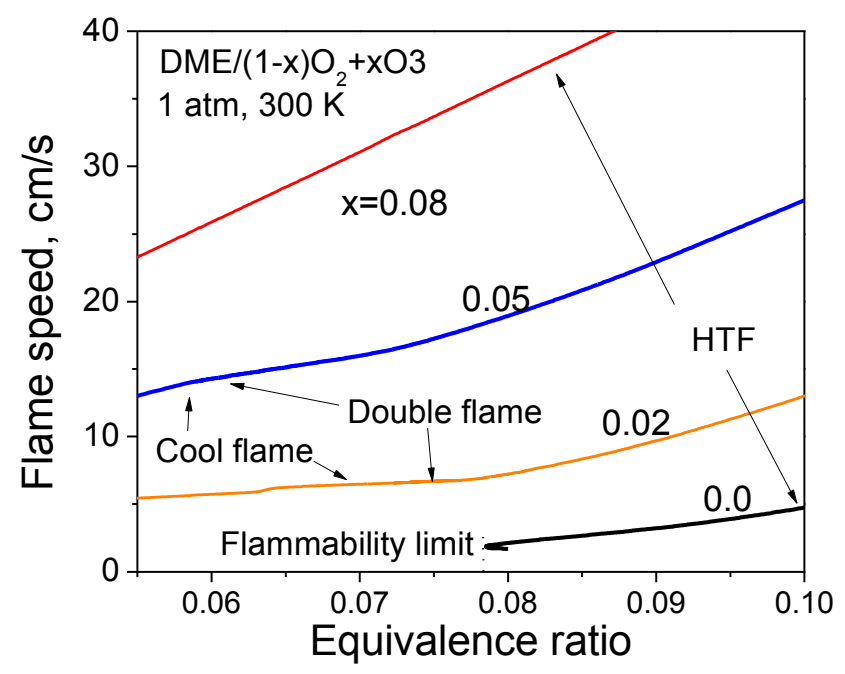

Fig. 7b Dependence of flame speed on equivalence ratio for $\mathrm{DME} /(1-\mathrm{x}) \mathrm{O}_{2}+\mathrm{xO}_{3}$ flames with difference percentages of $\mathrm{O}_{3}$ addition $(\mathrm{x}=0,0.02,0.05$, and 0.08$)$ at unburned mixture temperatures of $300 \mathrm{~K}$. 


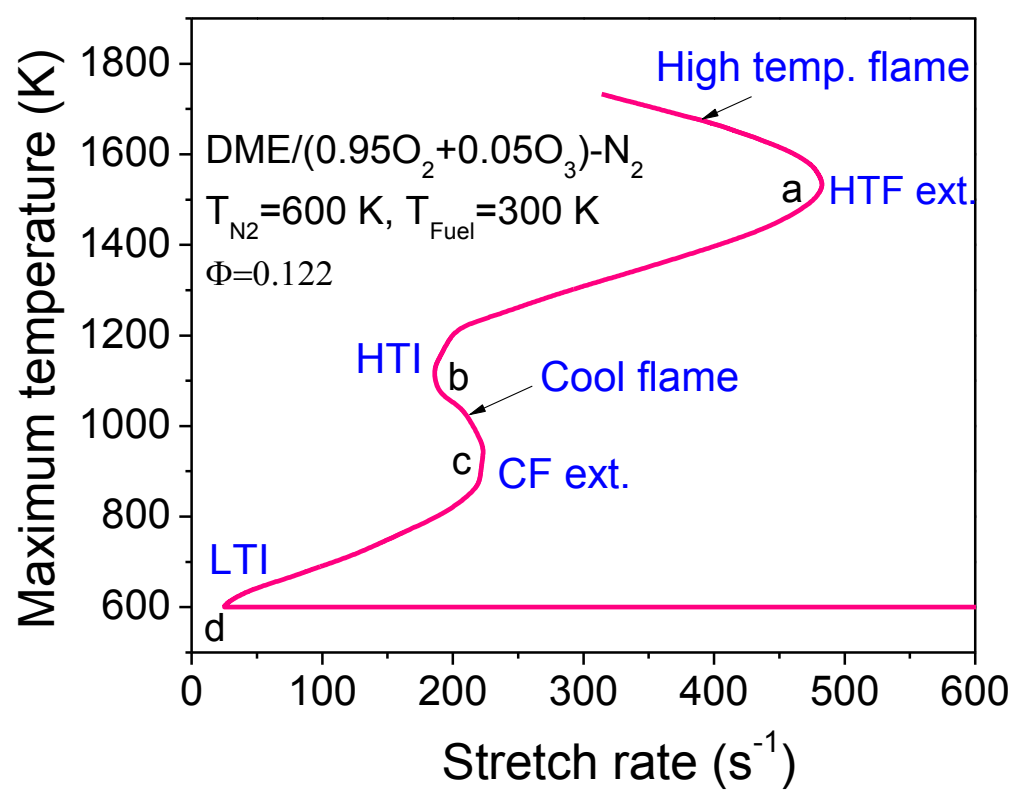

Fig. 8a Dependence of flame temperature on stretch for $\mathrm{DME} / 0.95 \mathrm{O}_{2}+0.05 \mathrm{O}_{3}$ counterflow flames at equivalence ratio of 0.122 , unburned mixture temperatures of $300 \mathrm{~K}$, and nitrogen temperature of $600 \mathrm{~K}$.

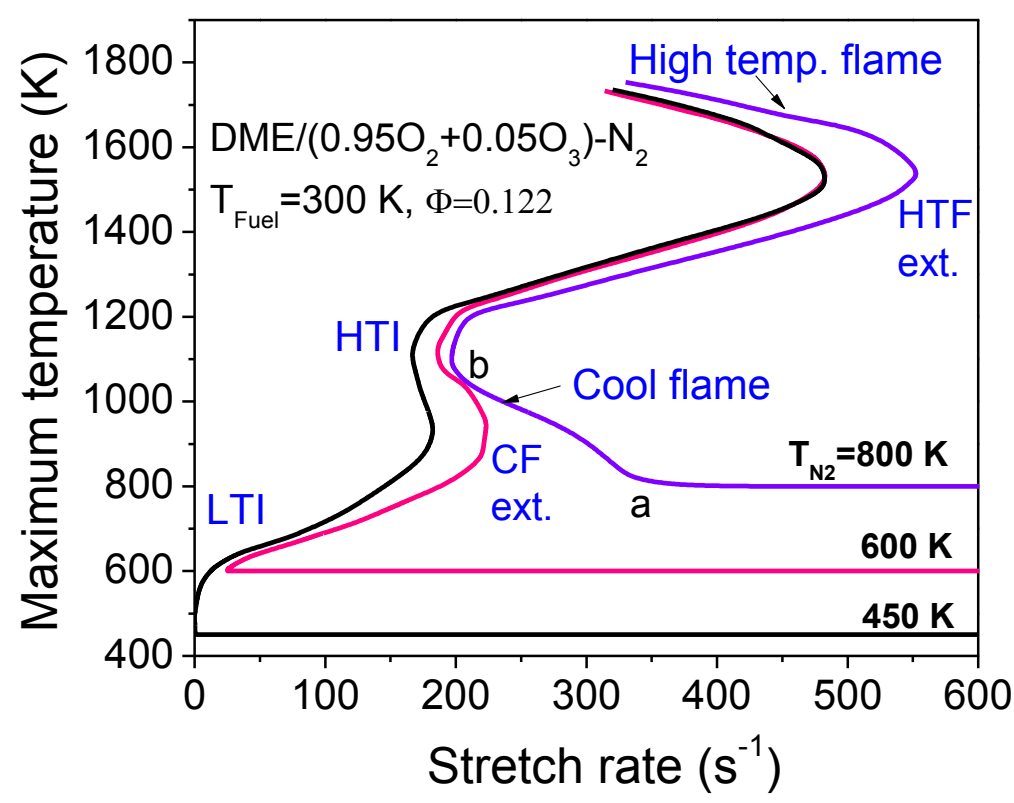

Fig. 8b Comparison of the dependences of flame temperature on stretch for DME $/ 0.95 \mathrm{O}_{2}+0.05 \mathrm{O}_{3}$ counterflow flames at equivalence ratio of 0.122 and unburned mixture temperatures of $300 \mathrm{~K}$ for different nitrogen flow temperature (450-800 K). 


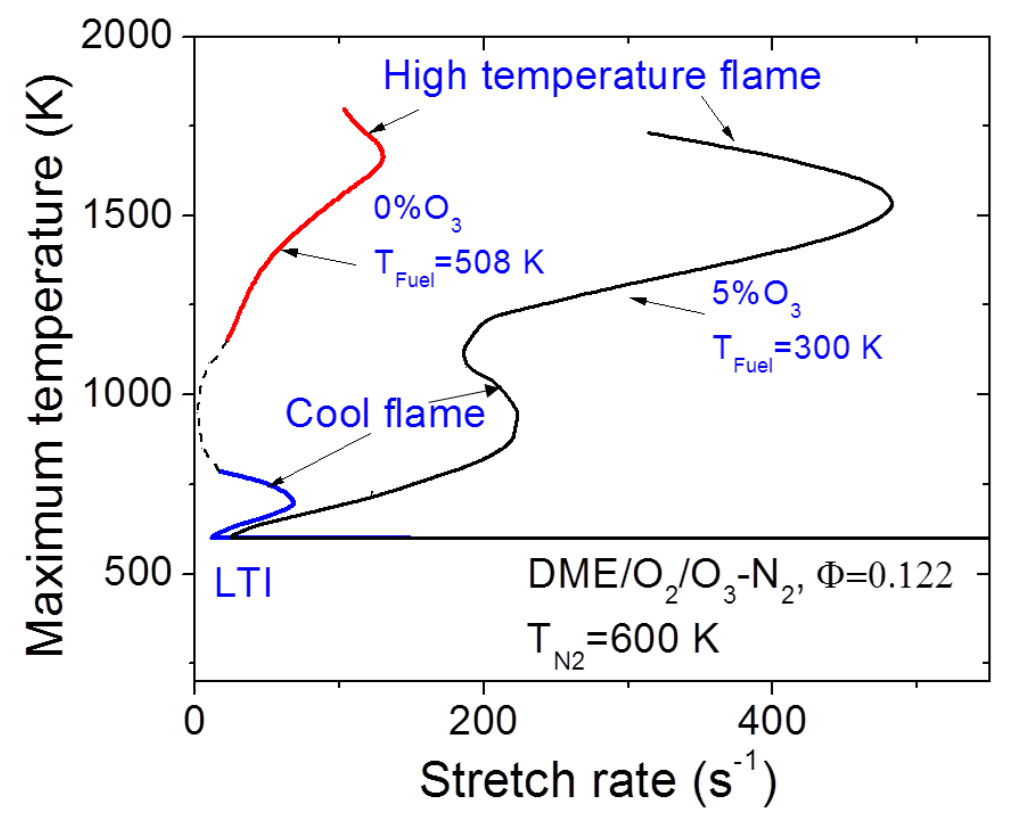

Fig. 9a Dependence of flame temperature on stretch for $\mathrm{DME} / \mathrm{O}_{2}$ counterflow flames at equivalence ratio of 0.122 , unburned mixture temperatures of $508 \mathrm{~K}$, and nitrogen temperature of $600 \mathrm{~K}$.

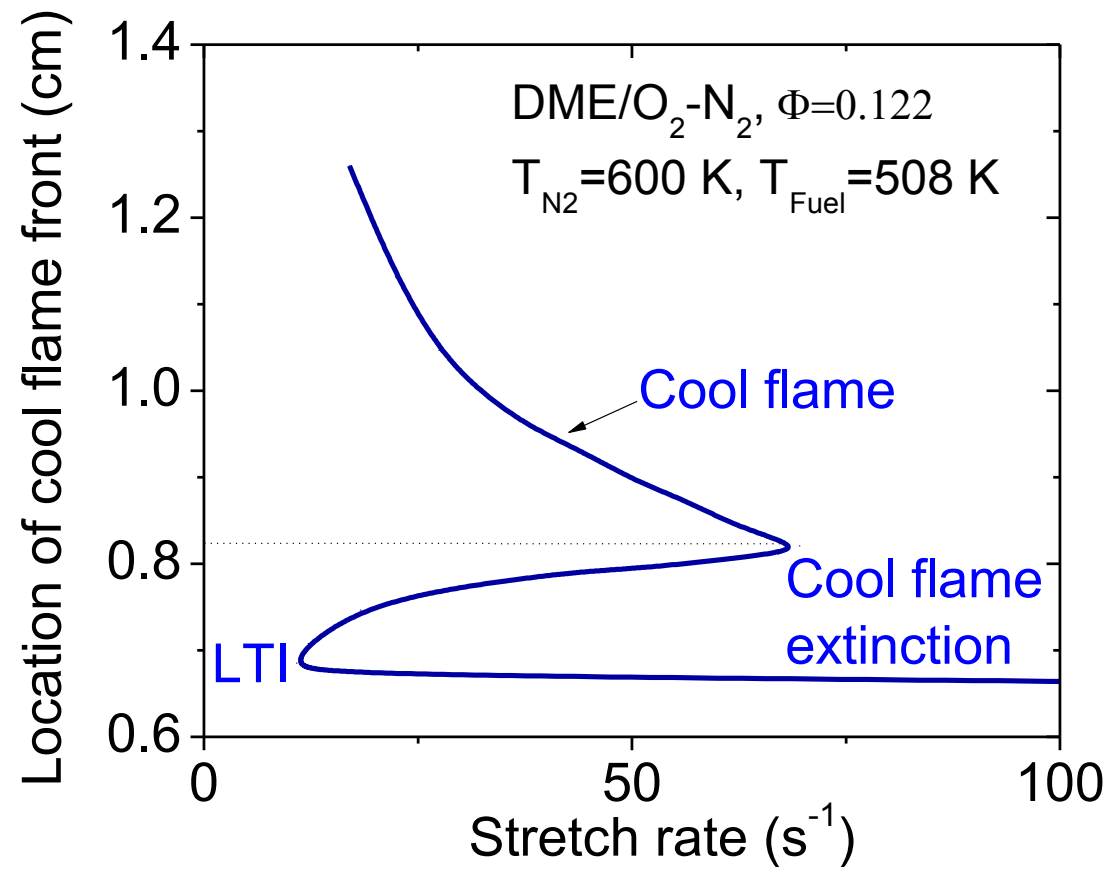

Fig. 9b Dependence of the location of cool flame on stretch rate for $\mathrm{DME} / \mathrm{O}_{2}$ counterflow flames at equivalence ratio of 0.122 , unburned mixture temperatures of $508 \mathrm{~K}$, and nitrogen temperature of $600 \mathrm{~K}$. The stagnation plane is located at $\mathrm{X}=0.75 \mathrm{~cm}$. 